\title{
'HOMM L'Homme
}

LHOMME Revue française d'anthropologie

$201 \mid 2012$

Varia

\section{Débat}

\section{(2) OpenEdition}

1 Journals

Édition électronique

URL : http://journals.openedition.org/lhomme/23004

DOI : 10.4000/lhomme.23004

ISSN : 1953-8103

Éditeur

Éditions de l'EHESS

\section{Édition imprimée}

Date de publication : 23 février 2012

Pagination : 163-163

ISSN : 0439-4216

\section{Référence électronique}

« Débat », L'Homme [En ligne], 201 | 2012, mis en ligne le 15 février 2014, consulté le 22 avril 2019.

URL : http://journals.openedition.org//homme/23004; DOI : 10.4000//homme.23004

Ce document a été généré automatiquement le 22 avril 2019

(c) École des hautes études en sciences sociales 


\section{Débat}

\section{Réponse à Catherine Tourre-Malen}

Dans le numéro 197 de la revue L'Homme (pp. 175-177), une jeune maître de conférence, Mme Tourre-Malen, a publié une recension particulièrement hostile à mon ouvrage $L a$ Nudité, pratiques et significations (Éditions du Cygne, 2008). Son texte ne présente aucun argument sérieux contre mon livre, mais procède uniquement par des allusions désobligeantes, qui semblent me reprocher certains détails comme le parti pris de traduire l'allemand Idealtype par la formule "idéal type" ("idéaux types" au pluriel) et, plus profondément, de procéder à partir d'une méthode a priori. Pour aller à l'essentiel, je tiens à souligner que la méthode des idéaux-types weberiens (je choisis en effet une traduction française du terme, comme le font beaucoup d'économistes, j'aurais pu aussi choisir "types idéaux" comme le fait Philippe Raynaud dans Max Weber et les dilemmes de la raison moderne) est précisément, par définition même, une méthode entièrement a priori, l'idéaltype étant toujours construit abstraitement puis mis à l'épreuve de la diversité des faits empiriques. C'est la méthode que j'ai choisie et qui respecte scrupuleusement l'enseignement de Weber. Mme Tourre-Malen, au lieu de la dénigrer avec arrogance, aurait mieux fait d'expliquer en quoi Max Weber ne lui paraît pas approprié à l'anthropologie contemporaine. Pour ma part, je trouve dans cette méthode le moyen d'accéder au maximum de neutralité et d'universalité (tout en préservant une forme de scepticisme quant à la capacité du "savant" à objectiver toutes les significations possibles de la nudité dans l'ordre de la pratique comme des représentations), en outre, les idéauxtypes assez englobants que je dégage sur cette base permettent de mettre en perspective l'anthropologie naturelle et l'anthropologie culturelle telles que les définit la tradition universitaire anglo-saxonne, un apport à la recherche qui fait d'ailleurs que mon ouvrage commence à être repris par certains de nos plus éminents collègues (par exemple, récemment, l'historien Jean Claude Bologne dans son dernier livre sur la pudeur féminine). La recension de Mme Tourre-Malen me paraît ainsi non seulement infondée, mais aussi symptomatique d'une dérive de la critique scientifique qui privilégie la posture au détriment de l'argumentation. Il serait regrettable qu'une telle tendance en vienne à envahir le débat entre chercheurs en sciences humaines dans les années à venir. 


\section{Christophe Coléra}

Réponse au compte rendu de Catherine Tourre-Malen paru dans L'Homme, 2011, 197 : 175-177.

\section{Réponse d'une jeune maître de conférence"}

Pour mieux servir sa défense,M. Christophe Coléra essaie de me faire passer pour "une jeune maître de conférence [sic]" - que sait-il de mon âge et de mon cursus ? - dont l'inexpérience présumée suffirait à expliquer les critiques que j'adresse à son œuvre selon lui parfaite en tous points. On ne saurait se montrer plus méprisant! Car si les défauts de son livre se limitaient au seul aspect qu'il relève, à savoir ses emprunts à la théorie weberienne, il ne s'agirait pas, après tout, d'un si mauvais livre. En réalité, j'ai formulé à son encontre bien d'autres critiques, que je ne saurais trop conseiller à cet éminent chercheur de prendre en considération, au lieu de camper sur une "posture" qui n'est guère de mise dans "le débat entre chercheurs en sciences humaines" qu'il invoque complaisamment.

5 Catherine Tourre-Malen 